Rasim M. Alguliyev ${ }^{1}$, Gulnara Ch. Nabibayova ${ }^{2}$

${ }^{1,2}$ Institute of Information Technology of ANAS, Baku, Azerbaijan

1' rasim@science.az, ${ }^{2}$ gnabibayova@gmail.com

\title{
SCIENTIFIC-THEORETICAL PROBLEMS OF ASSESSMENT OF INTER-COUNTRY INTEGRATION IN E-GOVERNMENT ENVIRONMENT
}

This paper studies various integration indicators of countries proposed by researchers and experts in a number of scientific works in order to study the inter-country integration processes. Following indicators are offered to solve issues related to determining the integration degree of one country to another in the e-government environment: the volume of information flows between countries' national domains on the Internet, the number of international meetings of representatives of state organizations and the number of international agreements signed between countries. Problem solution methods consisting of development of a decision support system using data warehouse technology and OLAP are demonstrated. Their brief characteristics are presented.

Keywords: inter-country integration, integration indicators of countries, e-government, decision support system, OLAP, data warehouse, weight coefficients.

\section{Introduction}

Obviously, today, integration processes are taking place between countries in various spheres. Depending on the context, they are distinguished:

- economic integration - the process of rapprochement, mutual adaptation and integration of national economic systems that have the capacity for self-regulation and self-development based on the agreed inter-state economy and policy;

- political integration - the process of rapprochement of political structures, aimed at the mutual cooperation;

- social integration - the process of establishing optimal links between relatively independent social entities.

However, in the context of globalization, it is very important to study the integration processes between countries in the e-government environment, to identify the integration indicators, and to determine the extent of integration of the country with other countries precisely in the e- government context.

The Latin word "integration" means "restoration", "completion", comes from the word "integer" - "whole". Hence, the concept is interpreted as follows: integration is the state of the connectedness of separate differentiated parts and functions of the system, the organism in a whole, as well as the process leading to such a state [1]. It is known that this term was first used in the 1930s by the German scientist C. Schmitt in his "Grossraum theorie" (theory of large spaces) [2].

When it comes to the notion of "integration of countries", in modern conditions it is, first of all, an involuntary and purposeful process of rapprochement, mutual adaptation, and subsequently, the fusion of political and financial national systems operating in them. This process has the potential of regulation and development, and is based on the interests of these countries, which indicate that the integration is a consciously regulated process. The main objective of the integration of countries is the search and expansion of cooperation forms and methods basing on and as a result of ensuring the effectiveness of activities on a local and international scale. Integration sharply increases the ability of solving problems qualitatively, while ensuring internal stability. The more solidary group of actors involved in the integration process, the stronger and more rational their impact on the system of international relations is [3].

This article examines various approaches to determining integration indicators with the purpose of studying the integration processes between the countries. The authors propose approach and the ways of implementing this approach in the e-government environment. 


\section{The choice of indicators for studying the integration processes between countries}

The analysis of the studies has shown that both research and commercial organizations show an interest in the study of integration processes between the countries. This is evidenced by a large number of publications in scientific journals and reports of scientific conferences.

The scientific literature devoted to this problem offers different methods and approaches to the determination of indicators and then the degree of integration of countries basing on them.

The article [4] shows the need for the assessment of the level of economic integration of the countries, which requires the identification of integration indicators. It is noted that this is important for the state policy, since, first of all, politicians must know the scale of integration for decision-making in this area.

The article examines the degree of institutional convergence or harmonization in different countries as the indicators of integration. The main argument here is that the countries can potentially integrate if the institutional barriers to cross-border economic flows are minimal. These obstacles are manifested in different forms: high import and export tariffs, non-tariff barriers, capital turnover controls, barriers to foreign direct investment (FDI), technology transfer and real estate transactions. If such obstacles are removed, the countries will potentially move towards economic integration.

Since the trade and FDI are two primary tools for accessing the foreign resources and markets, a combination of trade-based and FDI-based indicators is proposed for the integration assessment.

The article [5] describes the properties that the economies of the countries should possess to ensure the integration processes. They include:

- internal neutrality: economy, in which domestic demand is proportional to its share in the world economy, has a higher degree of integration;

- direct international neutrality: economy that establishes its direct relations with other countries proportionally to their size has a higher degree of integration.

- indirect international neutrality: economy that strengthens its relations with other countries through the third countries has a higher degree of integration.

- size: the larger the economy, the more relevant is its integration for the globalization of the world economy (the global degree of integration).

The authors indicate the indicators that they use to find the degree of integration. They include:

- the degree of openness of the country's economy;

- the degree of direct relations of the country's economy with the economies of other countries separately;

- the degree of direct relations of the country's economy with the economies of the other countries as a whole.

With the help of these concepts the followings have been determined:

- the degree of integration of the country's economy;

- the degree of the global integration of the country's economy with the world economic environment.

In [6], a three-step method is formulated to construct the composite index of integration.

The first step concerns the principles, on which separate indicators of the composite index of integration should be based: relevance, accuracy and reliability, availability of data, timeliness and consistency of data. These principles are often neglected due to the lack of indicators, and due to the obligatory use of incomplete or inaccurate data, which is caused by the multidimensionality of integration. Obviously, it concerns any method used to construct aggregated indicators. Nevertheless, in this approach, in contrast to others, the uncertainty of the data can be accepted, as well as the missing values can be adjusted by using statistical data. The second step is to classify the variables in accordance with specific aspects of integration, such as the indicators of the real process of integration and institutional characteristics. The third and final step consists of the 
construction of a composite index of integration, in particular, the determination issues of the weighting scheme for indicators (for example, statistical, etc.) and the aggregation method (for example, arithmetic mean, etc.).

The system of indicators of the Eurasian Development Bank includes three blocks corresponding to the three main aspects of the regional interaction [7]:

A) Analysis of the regional integration as the integration of markets. In this case, the convergence of the countries is estimated in terms of the scale of the flows of goods, services and factors of production between them. This block includes two groups of indicators:

- general indicators: trade integration and integration in the field of labor mobility;

- functional integration: integration interaction in three key areas of economic and social interaction of the countries of the CIS region (electric-power, agriculture and education).

B) Analysis of the regional integration as a convergence of economic systems. In this case, the convergence of countries is estimated in terms of similarity of the main quantitative characteristics of their economic development in four main areas: macroeconomics (growth dynamics), financial policy, fiscal policy and monetary policy;

C) Analysis of the institutional cooperation. In this case, the results of interaction between countries within the framework of formal integration projects operating in the post-Soviet space are assessed, taking into account the wide scope of the goals of these structures.

As a result of studying and analyzing these and other sources, it was found out that the proposed approaches and systems developed to study the integration processes and to define the degree of integration, the methods and calculations are used, which are based on economic indicators, such as quantitative estimates of import-export transactions, turnover, FDI, etc. These approaches can be considered convenient and sufficient in terms of an industrial society. However, they do not fully reflect today's realities. At present, in the globalizing world, in terms of the formation of the information society, when the knowledge economy is of great importance and information becomes a commodity and acquires commercial properties, this system cannot be considered complete for the study of the integration processes in the e-government environment. In these conditions, the scope of the integration processes is expanding, namely, the relations between the countries are also becoming really important on the Internet. That is, all currently available methods and approaches do not take into account such an important indicator of integration as information flows between the countries on the Internet.

Thus, in order to obtain more reliable assessment of integration processes in e-government, a new approach is required that takes into account the relations of countries in the virtual space expressed in the relations between the top-level domains of the countries, i.e., national domains. From this point of view, very useful and relevant information is concentrated in the web servers registers, the analysis of which will provide a real assessment of the integration processes.

All these prerequisites urge the further broader study of the integration of the countries taking into account the integration in the Internet.

Furthermore, the indicators such as the number of international meetings of the representatives of government organizations (GO) and the number of international agreements signed between the states can play an important role to obtain an even more complete assessment of integration processes in the e-government.

Taking into account all abovementioned, we can conclude that for a full analysis of the integration processes between the countries and considering the need to expand the scope of influence of the "e-government" and to expand the use of ICT at all levels of the governance, it is necessary to develop methods and algorithms for the assessment of the degree of integration of countries based on the indicators such as:

- $\quad$ the volume of information flows between the countries on the Internet;

- $\quad$ the number of international meetings of the government representatives;

- $\quad$ the number of international agreements signed between states. 
The obtained data is of great importance for effective and timely decisions in the field of international relations at various levels of governance, which in turn contributes to the organization of the right strategy in this area. Therefore, software products designed for this kind of information require constant updates, involvement of new data processing methods, and the use of modern data analysis and presentation technologies.

The development of OLAP-based (On-Line Analytical Processing) decision-making systems and the Data Warehouse (DW) will play a positive role in solving the presented task. The surveys have shown that OLAP and WD technologies have very favorable opportunities for online data processing and the delivery of finished reports. Additionally, the use of these technologies enables the system to be developed multifunctional.

\section{Conceptual bases for solving the problem of developing methods and algorithms for the assessment of the integration processes between the countries}

A sufficient number of methods have been developed to measure the degree of integration of countries thus far. Customs committees, statistical committees and other government bodies provide the relevant structures of objective information, on base of which the degree of integration of the country with another, as well as the global integration of the country with the rest of the world as a whole is calculated, using traditional and classical approaches and methods.

In this case study, we examine new approaches to determine the degree of integration of the countries in e-government in the context of globalization.

First of all, note that in the globalizing world, in terms of the formation of the information society, information becomes a commodity, in other words - is being commercialized. And available methods and approaches here are not sufficient. Obviously, in these conditions, integration processes between the countries are also observed on the Internet. These may include referring to web resources of other countries, communication via e-mail with other countries, etc. Thus, examining e-government to define the degree of integration of countries, we come to the conclusion that finding the integral index of integration, it is necessary to take into account the relations between the countries and on the Internet.

There are about two hundred countries in the world, for which top-level domain names are allocated. The official name of such a domain is country code Top-Level Domain, (ccTLD), such as, .az - for Azerbaijan, .ru /.pф - for Russia, .ua/..укр - for Ukraine, .de - for Germany , .bу/.бел - for Belarus, etc. Figuratively speaking, each country has two spaces - real and virtual (on the Internet). Furthermore, it is obvious that there are also some relations and links between the countries in the virtual space in the form of relations between their domain zones.

Fig. 1 presents a graph describing the information exchange between top-level domains of the countries.

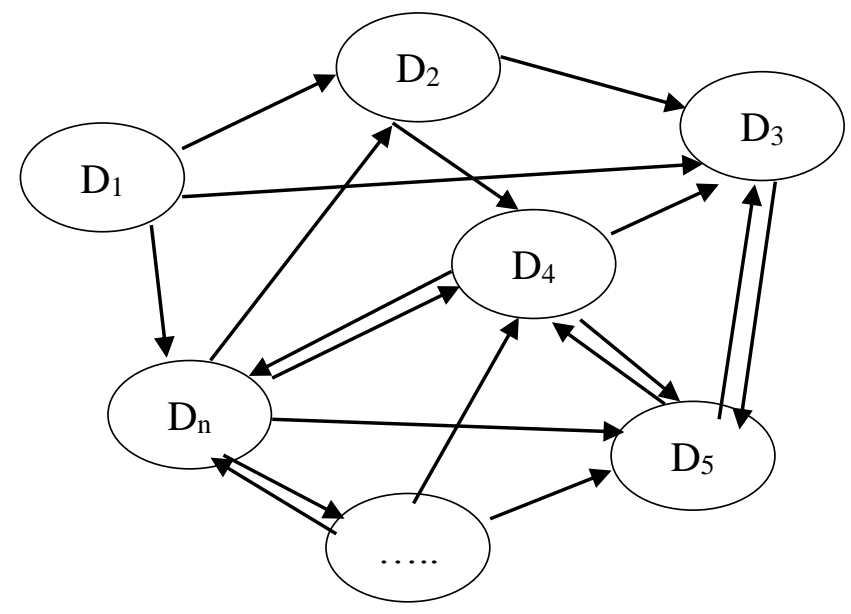

Fig.1. Exchange of information between top-level domains of the countries. 
The nodes $D_{1}, D_{2}, D_{3}, \ldots D_{n}$ of the graph are the top-level domains of the countries, the arrows $r_{12}, r_{23}, r_{13}, r_{45}, r_{54}$ etc. denotes the links between the domains, i.e., information flows between the domains.

Thus, the study of relations between the domain zones and the development of methods and algorithms for the assessment of the integration of the countries taking into account these relations will provide more complete assessment of the integration processes between the countries.

We examine one more indicator for the study of integration processes. It is known that, at present, each government is transforming into e-government, each government structure (ministry, committee, etc.) is transforming into an electronic structure, which means the formation of an information space of the e-government and each structure.

We will review the information space of the e-government, which is one of its important components.

Any GO accumulates large amounts of data in the course of its activity, which shape a certain corporate information space of the given structure together with the technologies attached to them for their maintenance and use, as well as with telecommunications. Corporate information spaces of all GOs as a whole constitute the information space of e-government, which is schematically presented in Fig. 2 [8].

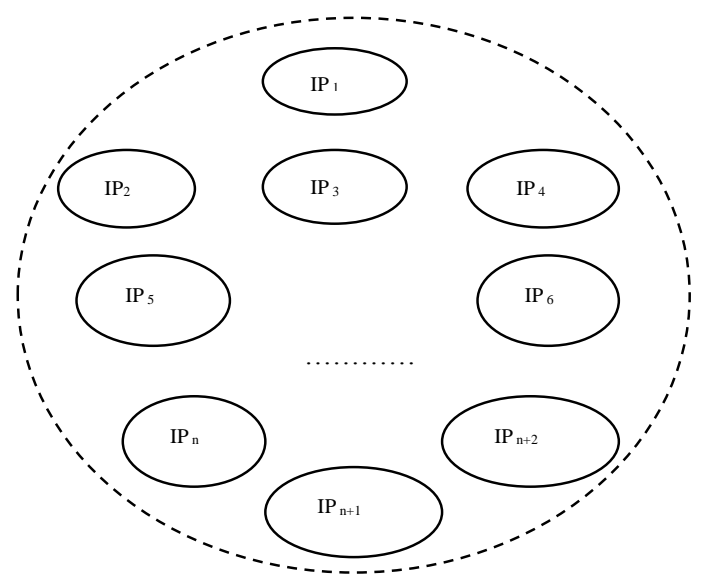

Fig.2. Scheme of information space of the electronic state.

Fig. 3 shows a schematic representation of the information space of GO. According to the scheme, the information space of GO is divided into three blocks:

- informational resources

- information technology

- telecommunications

Today, one of the most important activities of any civil society is the formation and development of its international relations. In recent years, international relations have been dynamically developing, expanding in scale and geographically. The success of an organization in the sphere of international relations as in the sphere of science, technology, education, material production, etc. depends on to which extent the organization is able to make the most efficient use of the information resources at its disposal. 


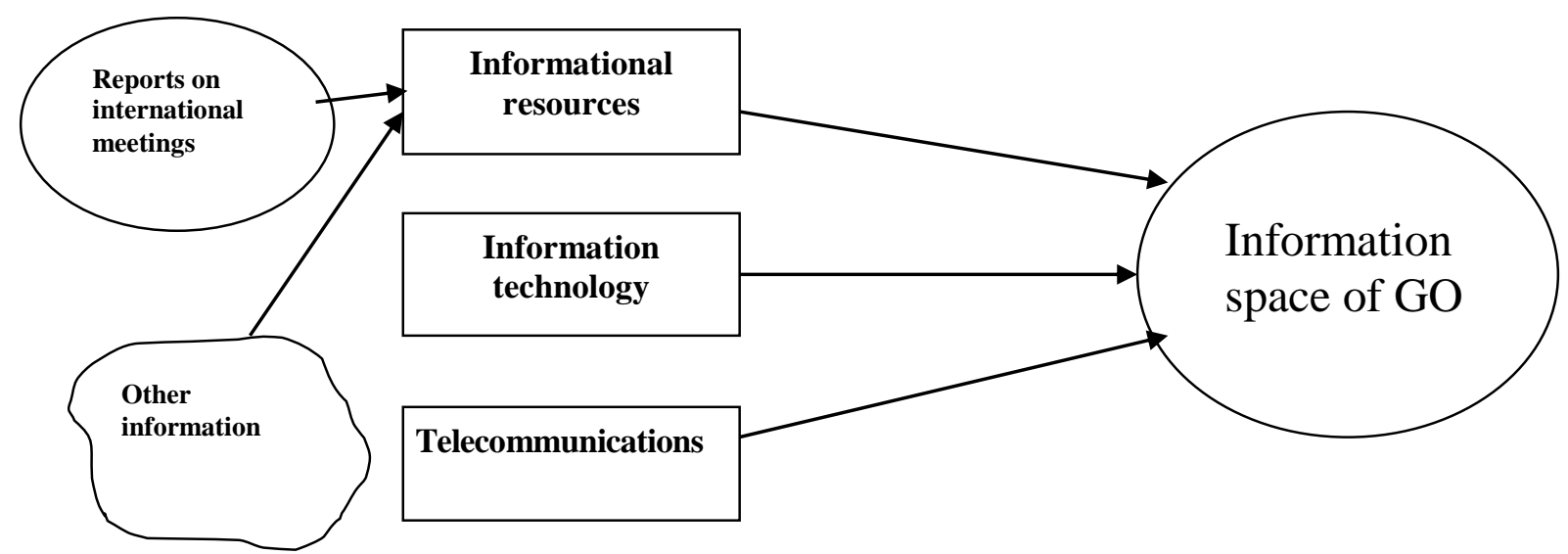

Fig.3. Scheme of information space of GO

Reviewing the block "informational resources", it should be noted that its certain part consists of such an implicit and non-surface segment, however very important for the solution of certain tasks, as reports on international meetings of the representatives of GO (both the departure of its representatives, and arrival of foreign representatives). [8-10]

The surveys have shown that there are historically developed management methods that do not meet modern requirements. Management in these organizations is limited to solving a number of local accounting and reporting tasks based on outdated hardware and software. The results of the introduction of ICT in public authorities, currently, are mainly of a departmental nature. And as a consequence, all reports on the international meetings of the representatives of GO containing important operational, historical and reference information are stored in paper or electronic form in the archives of various departments of the government institution - human resource department, accounting department, research and organizational department, etc., i.e., the storage of this information is unorganized and unsystematic. Consequently, it is practically unavailable for use for certain purposes, if necessary.

A new approach allows extracting information from these reports for the assessment of the integration. Namely, another indicator can be obtained for the assessment of the integration processes by combining data on the international relations from all these information resources. Thus, the information of GO about the international meetings can be another important indicator for assessing the degree of integration of the countries.

Another important characteristic of the integration processes is the international agreements signed between the countries.

An international agreement is governed by the international law signed by the governments and/or other bodies of the international law [11]. It includes agreement, contract, convention, the charter of an international organization, protocol, pact, etc.

International agreements promote rapprochement and the integration of the countries. In addition, it should be noted that many of them are aimed at the creation of the international unions. All of these is an important factor of that the international agreements signed between the countries should also be considered an important indicator.

The annual increase in the volume of information related to the integration of the countries contributes to the growth of the data base, which complicates the process of analyzing this data and obtaining results. For the development of the methods and algorithms to determine the integration of the countries, taking into account such problems, it is proposed to use DSS. It is capable of processing large volumes of heterogeneous, constantly incoming information and transforming disparate, scattered information into valuable knowledge, on the basis of which it will also be possible to make intentional and calculated decisions, which are aimed at increasing the effectiveness of GO, rather than the intuitive and improvisational decisions. 
The objectives and tasks of this DSS are to provide the managers of organizations or departments working in this field with up-to-date and relevant information related to the relations of the countries on the Internet, i.e., relations between the national domains, as well as related to the international meetings of the representatives of GO and signed international agreements. Additionally, the use of modern methods of working with available information will give the analysts a holistic picture of the development of the structure in various fields, which shows the multi-purpose nature of the DSS. It means that it can solve the management problem in various aspects - management of personnel, financial and technical resources.

The proposed DSS will contribute to the performance of both managers and analysts. It will enable the managers to:

- timely make effective management decisions;

- acquire reliable information about the current state of affairs in the organization;

- create an adequate information model of the enterprise;

And the analysts with its help will be able to:

- create own archive of documents;

- promptly search, evaluate and systematize information in the archive;

- conduct overview, comparative and dynamic analysis;

- develop hypotheses;

- predict the development of the situation;

- compile reports and reports.

The core of DSS is the technologies that use modern methods of collecting, storing, analyzing and processing the information, due to which a comprehensive data mining, namely DW and OLAP, is carried out.

The Fig. 4 shows the enlarged architectural and technological scheme of the information and analytical decision support system [12], adapted to our task.

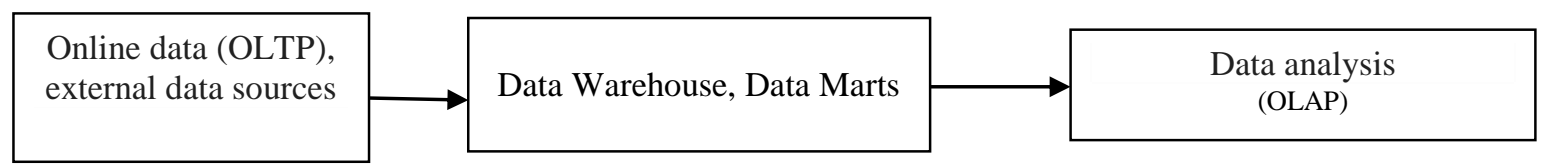

Fig. 4. Architectural and technological scheme DSS

DW technology, which is one of the main links of the DSS architecture, is developed on the basis of improving the database technology. Typically, DW consists of basic data, historical data, integrated data and metadata. This can provide a comprehensive analysis, analysis of time trends and other information supporting decision-making. DW is a subject-oriented, integrated, stable, time-related and unchanging set of data.

DW is the basis for decision-making and analysis. However, the data in DW cannot be directly used by the managers. To extract the knowledge and information from the data, various analytical tools are used that are close to decision-makers. OLAP is one of such tools. OLAP converts the data in DW into a multidimensional cube, analyzes the current and historical data, and then generates special queries and reports in a multidimensional environment to assist decision-making [13].

\section{Conclusion}

Today, in the modern world, the situations often arise when the governments are not able to independently cope with complex economic, political, social, environmental, scientific, technical and other problems. For their solution, they are trying to unite the efforts with the efforts of other countries, that is, to integrate to jointly overcome the new challenges of the 21 st century. 
The processes of integration can be observed in different fields. Nowadays, in the context of globalization, which is topical in the 21 st century, it is important to study the integration processes of the countries in e-government and to identify the integration indicators for the study of these processes. The article showed that in this sense, important indicators of integration are: the volume of information flows between the national domains of the countries on the Internet, the number of international meetings of representatives of GO, and the number of international agreements signed between the countries. Determining the degree of integration of the countries, on the basis of these indicators, provides an opportunity to see all these processes from the inside, analyze them, forecast, and identify the trends in further development of interstate relations.

\section{References}

1. Makhov A.E., Petrovskaya L.I., Smolkin V.M. The Great Russian encyclopedic dictionary. Moscow: The Great Russian Encyclopedia. 2003

2. Chernov Zh.B. Analysis of scientific approaches to the economic nature of the cluster / / Internet-journal "Naukovedenie", 6 (25), 2014, pp. 1-10.

3. Chelyadinsky A. The concept of integration in the international relations: theoretical aspect. Journal of International Law and International Relations, 2009, No. 1, pp. 29-32.

4. Prakash A., HartJ. A.Indicators of economic integration / Global Governance 6, 2000, pp.95-114.

5. Arribas I., Perez F., Tortosa-Ausina E. Measuring globalization of international trade: Theory and evidence. World development, 2009, vol.37, no 1, pp.127-145.

6. De Lombaerde P., Dorrucci E., Genna G., F. Mongelli P. Composite indexes and systems of indicators of regional integration // The Regional Integration Manual. Routledge / Warwick studies in globalization, Routledge, 2011, pp.323-346.

7. System of Indicators of Eurasian Integration of the EDB 2009, Almaty: RUAN, 2010,160 p.

8. Nabibayova G.Cj. Development of an information and analytical decision supporting system in the field of foreign policy // Information Society Problems, 2010, No2, pp. 62-72.

9. Alguliev R.M., Nabibayova G.Ch. On the conceptual foundations of the development of an information and analytical decision supporting system in the field of foreign policy // AzTU, Scientific works, 2009, No1, pp.3-5.

10. Nabibayova G.Ch. Application of OLAP-technologies in decision support systems in the sphere of foreign policy // Information Technologies, 2012, No2, pp. 73-76.

11. https://ru.wikipedia.org/wiki/International_Contract

12. Volkov I., Galakhov I. Architecture of the modern information-analytical system. "Director of IP”, No. 3, 2002.

13. Nabibayova G.Ch. Exploring the possibility of using decision support systems in the e-government environment // Information Technology Problems, 2015, No2, pp. 88-95. 